\title{
The Ingredients for Innovation: impacts for practice and the education of health service managers
}

Sheree lloyd; Sarah low; Su lei Win; Gerard Fitzgerald; Cynthia Cliff; Jean Collie

Sheree Lloyd B. Bus(Computing), MTM, PhD Candidate (QUT), Assoc Dip, MRA, Dip Govt, Dip Project Management AFCHSM, CHIM.

Sarah Low Master Health management, Bachelor Health Science (HIM) (QUT, PhD candidate (Utas)).

Su Lei Win MBBS (Ygn), Master of Health Service Management MBBS

Gerard Fitzgerald MB BS, BHA(NSW), MD (QLD) FACEM FRACMA FCHSM

Cynthia Cliff BSc(Hons), PhD, ARACl, Grad Dip Env Stud, Grad Dip Outdoor Ed, Grad Dip Bus Mgt, GAICD

Jean Collie $M B B S$ (UQ)

MHP (NSW) FRACMA, FAFPHM

Correspondence: s.lloyd@griffith.edu.au

\section{Abstract}

Background: Innovation is associated with improvement, however, there is little published about the 'ingredients' for successful innovation in healthcare, and the skills required of Health Service Managers (HSMs) who facilitate change in their organisations.

Aim: This paper synthesizes the findings of a literature review performed to describe the organizational and contextual factors that enable and sustain innovation in healthcare settings. Implications for the practice of Health Service Management and curriculum development have been extrapolated as innovation has been identified as a solution to escalating health system demands in a rapidly changing environment.

Approach: A literature review used a systematic approach to source articles from the Scopus and Emerald databases over the period of 1993 to February 2016. Papers were also retrieved from a BMC Health Services
Research weekly alert. Snowballing from relevant articles identified additional and significant papers. Grey literature, peerreviewed papers and reports were similarly reviewed to incorporate contemporary perspectives on this topic across the business, health and University sectors, and to facilitate discussion of the skills and competencies for HSMs practice and education in relation to this topic.

Context: Innovation is crucial to the sustainability and viability of Australia's world class health system. There is potential for innovation to lead to more cost-effective and efficient ways to address the challenges of limited health budgets and increasingly complex morbidities in an ageing population.

Main Findings: Successful innovation according to the literature, is determined by a complex interaction of determinants including organizational culture, support and resourcing for innovation, leadership and a clear and 
shared vision. An organizational culture supportive of innovation includes strong transdisciplinary communication, engaged and invested staff and recognition of the role of innovation in health improvement and outcomes. A setting that is open to identifying, testing and evaluating initiatives for innovation requires capabilities to establish and maintain the working relationships, team dynamics and to prioritise resourcing to facilitate and sustain new ways of working, services, products or technologies.

Recent research on the skills required for health service management employability and career success was also examined and identified the importance of skills such as communication, creativity and problem solving. These skills are critical and linked to the role of the HSM in accelerating innovation in their organisations.

Conclusion: The key ingredients for successful innovation in health were inferred from the literature. HSMs are well positioned to support innovation as they possess the necessary technical and professional skillsets.

\section{INTRODUCTION}

Delivering cost effective, responsive and safe health services is critical for the funders, providers and the consumers of healthcare in Australia. A healthy population is also essential for the prosperity and economic well-being of the country. Australian health settings face many challenges in coping with the volume of services they provide, changing consumer requirements and the types of health problems experienced. Consequently, health service managers perceive that innovation and the implementation of new models of care, practices, information communication and technologies can be identified, adapted and
The literature suggests that the development of graduate skills in the areas of communication, problem solving, and team work is critical to meet industry needs and for HSMs to enable innovation.

Universities educating health service managers strive to ensure that graduates are professionals equipped to lead and manage health services. HSM graduates can foster the organizational and contextual factors that sustain and sanction innovative ideas to flourish and progress to implementation. Current research advocates that strong industry and higher education collaboration is important to further develop the graduate attributes necessary for innovation.

Keywords: performance, innovation, education, technical skills, generic skills

sustained to ensure the future viability and safety of our health care system.

\section{BACKGROUND}

Australia's health system is acknowledged as performing well when compared to similar countries and economies and accomplishes these relatively efficiently and cost effectively. [1] However, there is scope for reform at the macro and micro levels of the Australian healthcare system. [2, 3].

The Australian Government's Productivity Commission stated that there are a range of 
'within system' reforms that can improve health outcomes. These include accelerating creation and diffusion of effective care delivery innovations. [4] The Productivity

Commissioner's more recent report of 2017 notes that it is important to focus on 'ways of encouraging devolved innovation, experiments and diffusion of evidence-based healthcare and administration'. [5] A major report by the Department of Industry, Innovation and Science [6] linked innovation to Australia's future prosperity and a means to navigate a rapidly changing future.

International bodies identify that healthcare performance and improvement are dependent on the quality of health professionals managing the healthcare organisation and innovation features on agendas of government, industry and universities in Europe, United Kingdom and the United States. $[7,8]$

Health Workforce Australia communicated in their LEADs framework that health leaders should 'drive innovation' and contribute to the 'spread of innovation' through initiation, momentum for change and system improvements. [9]

Health Service Managers in Australia are educated in the higher education sector and complete programs that develop technical, professional and generic skills in their graduates. Recent studies of graduate and industry employers in Australia reflect the importance of generic skills and a requirement for capabilities such as creativity, problem solving, communication, collaboration, selfmanagement and teamwork. [10,11] Innovative thinking in health service management post-graduate courses in Australia was examined in a study by Isouard, Martins, \& Friedman. [12] Whilst acknowledging limitations, their study indicated that innovation, creative and innovative thinking did not feature prominently in the courses they explored. The authors urged that the best location and means of delivery for enhancement of these skills, such as professional development or mentoring programs or gained through training in the workplace be considered. [12]

This paper synthesizes the findings from the literature and has drawn inferences to determine the ingredients for innovation, the role of HSMs in successful innovation and to promote discussion among practitioners and educators.

\section{METHODS}

A review of the literature was conducted identifying articles from Scopus and Emerald databases. The snowball method identified significant articles and a weekly alert from BMC Health Services Research recommended relevant papers for review. As an emerging topic the grey literature and government reports were also appraised. Papers were screened, evaluated for their contribution and grouped in to the themes to form the basis for the following discussion.

Additional papers on the skills and competencies for health service managers were sourced to support the discussion on the application of the findings for practice and educational purposes.

\section{FINDINGS}

\section{Innovation in health care defined}

Many definitions for innovation appeared in the literature and the topic is complex. Greenhalgh, Robert, Bate, Macfarlane, \& Donaldson, [13] in a systematic literature review defined innovation in health service delivery and organization as 'behaviours, routines and ways of working, along with any associated administrative technologies and 
systems'. Further these innovations must be perceived as new by stakeholders, linked to the support or provision of healthcare, and aimed at improving administrative efficiency, health outcomes, cost-effectiveness, efficiency, patient or carer experience and implemented by the action of individuals, organisations or teams. [13] Omachonu \& Einspruch, [14] define innovation in health as 'the introduction of a new concept, idea, service, process, or product aimed at improving treatment, diagnosis, education, outreach, prevention and research, and with the long-term goals of improving quality, safety, outcomes, efficiency and costs'.

From the wider literature, Damanpour [15] defines innovation as the 'generation, development, and implementation of new ideas or behaviours'. Furthermore, innovation is a means of changing an organisation and can be broadly defined to include types of innovations that might be new products or services, new process technologies, new organisational structures or administrative systems, or new plans or programs. [15]

Gault, [16] proposed a general definition of four types of innovation. A product innovation is new or significantly changed with respect to its characteristics or intended uses. A production or delivery innovation is the implementation of new or significantly changed delivery or production processes. While marketing/communication innovations are the implementation of a new or changed method of promoting the products of the organisation. Finally, organisational innovations are new or changed methods in business practice, workplace organisation or external relationships.

Healthcare innovation determinants to identify, sustain and disseminate innovation

To effectively identify, sustain and disseminate innovation requires a multi-faceted approach and is the result of many antecedents and determinants. $[17,18,19]$ Innovation success or failure can be influenced by management support for the innovation, appeal of the innovation, size of the organisation, positive organisational culture, organisational learning, effective leadership for innovation and performance and teamwork. $[17,18,20,21]$

Crossan \& Apaydin [21] describe leadership, managerial levers and business processes as determinants of innovation as well as impediments to innovation such as conflict, lack of infrastructure, and external disruption. In a systematic review of the literature, Crossan \& Apaydin, [21] identify organisational determinants such as professionalism, organisational structure, strategy, organisational learning, positive climate and financial resources as determinants of innovation in the existing research. Their study resulted in a multi-dimensional framework of organisational determinants of innovation grouped at the environmental, organisational and group levels. [21]

Innovation can be transformational, but most innovations are combinations of elements that already exist. According to Salter \& Alexy [22] incremental, ongoing, smaller innovations can have significant impacts. Rao \& Weintraub $[23,24]$ highlight that resources, processes and measurable performance outcomes often receive more attention than the crucial 'people oriented determinants of innovative cultures' such as values, behaviour and organisational climate which are often difficult to measure.

To sustain innovation Fox, Gardner, \& Osborne, [25] suggest a framework around five factors that include innovation specific, workforce, organisational, political and financial factors. Clear communication, financial support, education and staff training, appropriate 'organisational fit' of the innovation, staff involvement in the implementation and decision-making around 
the innovation will determine sustainability. [25]

Greenhalgh and her colleagues [26] and [13] created a unified model from their synthesis of the literature and identified that to diffuse innovations in health services a complex interplay of system antecedents, readiness for the innovation, the 'innovation itself', leadership, vision, resourcing and organizational climate is required.

Determining if innovations will succeed or fail depends upon many 'moving parts' and is reliant upon the implementation context and the approaches utilized to reinforce an innovation. [20]

\section{HSMs and their role in healthcare innovation}

Martins \& Isouard, [27] discuss a comprehensive framework of predisposing, enabling and transforming competencies for health service management with innovative thinking, relationship building, effective communication and interpersonal understanding among the key skills identified.

Melder \& Killion [28] highlighted the need for health care leadership and policy makers to support system wide innovation and redesign in healthcare, citing the 'significant and consistent' evidence in the current literature. The role of HSMs they outlined is to provide motivational leadership towards improvement strategies aligned with a vision and investment in staff and resources for 'transformational change. [28]

Clinicians wanting to improve patient care and adopt innovation can drive innovations within a health care organization and the drivers for innovation in healthcare can be internal or external. Innovation can be driven by the need for reform and change compelled by the consumers of healthcare, internal/external stakeholders, government policy, accrediting bodies and legislation.

Health Service Management graduates across Australia are educated in the higher education sector in management, leadership, project management, financial management and health informatics. Australian universities seek to develop in their graduates a number of attributes such as communication, collaboration, intellectual enquiry and analytical skills, lifelong learning, effective and capable in diverse and international environments, innovative, creative with discipline specific knowledge and skills. $[29,30,31]$ Nevertheless, in a study that reviewed 13 postgraduate courses in health management across Australia, Isouard and colleagues [12, p266] found that innovation, creative and innovative thinking were not prominent in course content despite the 'importance of this management competency to deal with a changing environment and health services practices'.

The Australian College Health Service Management Competency Framework identifies leadership, communication and relationship management, professional and social responsibility as key domains on which HSM education programs should be based and to guide the employment, management and mentoring of HSMs by employers and policy makers. [32]

Graduates prepared for a rapidly changing and technological world will require new skillsets. The most commonly mentioned skills for the future identified in education policy documents across 150 countries were communication, creativity, critical thinking and problem solving. [33]

A study on employability skills for HSM graduates by Messum and colleagues, [10] identified generic capabilities (communication, 
intrapersonal and interpersonal, teamwork and collaboration) as most relevant to employment. Skills that were most valued were communication, teamwork, flexibility, open-mindedness, networking, priority setting, integrity and ethical conduct. [10] Other work by Messum et al [34] found that conceptual and analytical skills were regarded as important and that higher education is showing interest in generic skills because of pressure from employers. [35]

\section{DISCUSSION}

The thematic analysis of the literature identified the types and determinants for innovation. The findings of the literature review suggest that to maximise opportunities through innovation for improved processes, services, products or technologies that the right 'mix' of ingredients are required.

To ensure that the health system can provide comprehensive solutions into the future, new models of care, communication methods, processes, technologies and the creation of new connections and growing partnerships will be essential. Team building and the ability to collaborate and solve problems will be critical capabilities. Identification of information, technology and communication systems that facilitate and support health care professionals to perform their roles and provide the best possible care is necessary for innovative ways of working. Using information to determine where innovation can occur and to drive evidenced-based decisions will be critical.

Programs in health service management in higher education institutions equip their graduates with skills and knowledge in change management, leadership, project management, financial management and health informatics. Professional bodies in health service management also recognise the interrelationship between skills such as communication and relationship management, professional and social responsibility and business skills. [32]

Generic and technical skills are increasingly valued by employers with conscientiousness (being organized, responsible, hardworking) and interpersonal and intrapersonal competencies, the most highly correlated with career and educational outcomes. [36,37]

Graduating students with strong communication and interpersonal skills, selfawareness, planning, collaborative ways of working and desire for lifelong learning, open mindedness, ethical conduct and teamwork skills are important to health service managers that employ our graduates. [34]

Leaders through their vision and the setting of goals can enable innovation by creating a climate, providing the resources and promoting the organisational values that encourage innovation. Identifying areas for improvement based on data and using this to identify the causes of poor performance, quality and safety issues, opportunities to reduce waste, and reduce delays will stimulate innovation.

Health Service Managers play a vital role in setting the vision and strategy that guides the structure, allocation of resources, design and culture of an organisation that are critical for innovation. [38] 
Identification of information, technology and communication systems that release health care professionals to perform their roles, provide time for thinking and creative problem solving and to provide the best possible care is necessary to identify and implement innovative ways of working. Health service managers can foster team building and use diversity within their organisations to solve the complex problems facing our health services. Applying generic capabilities and skills such as relationship building, problem-solving and communication will be key to accomplishing new ways of working.

Job ready graduates, prepared through engagement with challenging tasks, who are able to reflect on their learning and practice, and who have been exposed to realistic cases integrated into their learning will develop the problem solving and collaboration skills, required by health service managers to build cultures and environments where innovation can flourish. [37]

Messum et al. [10,34,35] propose that working partnerships between the higher education sector and the health industry to build real world challenges into assessments could better equip students for the changing workplace. Others recommend building employability skills through skills such as simulation, action learning and assessment linked to learning goals. $[37,39]$

Innovation adoption in health is complex with many antecedents and determinants identified by the literature review. Distillation of the findings indicate that health service managers for the future should leverage their generic and technical skills to support clinicians and managers to innovate. The literature review findings have been extrapolated and propose key 'ingredients' for innovation in health. This is shown in the diagram below.

\section{Innovation in complex health organisations}

\section{Types Determinants Ingredients}

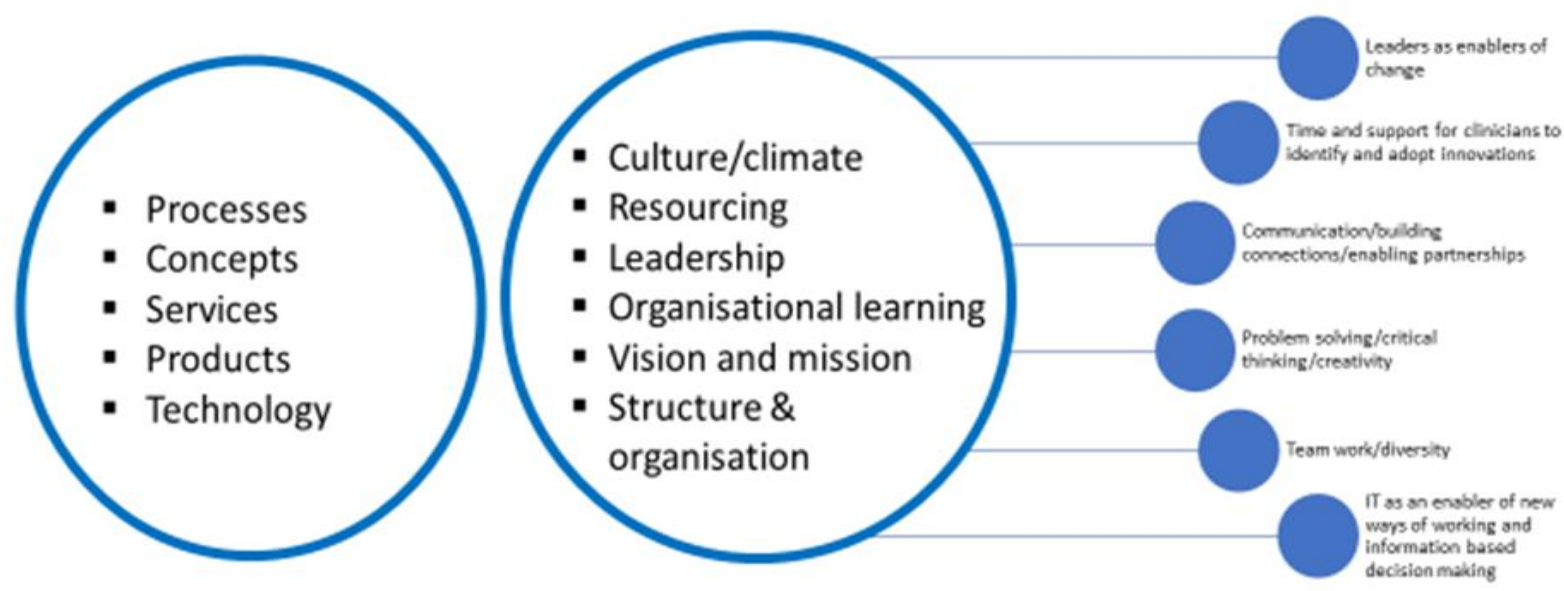




\section{LIMITATIONS}

This study has some limitations, primarily the papers in this study were reviewed by one individual as part of their PhD candidacy. Multiple reviewers would provide further rigor to article selection and interpretation. Literature, specifically on health innovation is limited. Papers, through necessity were drawn from other industries where most research on this topic has been conducted. Healthcare is a unique industry, with many layers, parts and stakeholders working together to deliver care. Innovation could play out differently in settings depending upon the organizational and contextual factors evident.

Innovation is an emerging national priority in Australia and globally. Further research as to how health service managers can support and provide the climate and conditions for innovation in their organisations is encouraged. This would enhance the understanding to inform health service management programs and educators.

\section{CONCLUSION}

There are many ideas to improve and redesign health for better outcomes but 'spending more on the current system will generate more healthcare of the same quality' (Tomson 2009). Health service managers have an opportunity to support a climate for innovation, support and enable the introduction of new ideas, new models of care and new ways of working.

Future graduates must understand the pivotal role of innovation in our health care systems and further develop the generic capabilities that will enable them to influence and enable innovation.

\section{Reference}

1. Organisation for Economic Co-operation and Development. Health at a Glance 2015. 2015.

2. Duckett S, Willcox S. The Australian Health Care System. 5th ed. Oxford University Press; 2015. 3. Wutzke S, Benton M, Verma R. Towards the implementation of large-scale innovations in complex health care systems: views of managers and frontline personnel. BMC Res Notes [Internet]. BioMed Central; 2016;9(1):327. Available from:

http://bmcresnotes.biomedcentral.com/articles/10.118 6/s13104-016-2133-0

4. Productivity Commission. Efficiency in Health: Productivity Commission Research Paper [Internet]. 2015. Available from: www.pc.gov.au

5. Commonwealth of Australia. Shifting the Dial : 5 Year Productivity Review. 2017.

6. Commonwealth of Australia. Australian Innovation System Report [Internet]. 2017. Available from: https://industry.gov.au/Office-of-the-ChiefEconomist/Publications/AustralianInnovationSystemRep ort2017/index.html

7. European Commission. Europe 2020 A strategy for smart, sustainable and inclusive growth. Vol. 1. 2010.

8. Parris S, Cochrane G, Marjanovic S, Ling T, Chataway J. Galvanising the NHS to Adopt Innovation: The Feasibility and Practicality of Recommendations from the Interim Report of the Accelerated Access Review. Rand Heal Q [Internet]. 2016;6(1):8. Available from:

http://www.ncbi.nlm.nih.gov/pubmed/28083436\%0Aht tp://www.pubmedcentral.nih.gov/articlerender.fcgi?arti $\mathrm{d}=$ PMC5158272

9. Health Workforce Australia. Health LEADS Australia: the Australian health leadership framework. 2013. 10. Messum D, Wilkes L, Jackson D, Peters K. Employability Skills in Health Services Management: perceptions of recent graduates. Asia Pacific J Heal Manag. 2016;11(1):25-32.

11. Briggs DS, Isouard G. The Language of Health Reform and Health Management: critical issues in the management of health systems. 2016;38-45. 12. Isouard G, Martins JM, Friedman LH. Competency in innovation, creative and innovative thinking: challenges within the Health Management course curriculum. J Heal Adm Educ Summer. 2015:

13. Greenhalgh T, Robert G, Bate P, Macfarlane F, Donaldson L. Diffusion of Innovations in Health Service Organisations: A Systematic Literature Review [Internet]. Chichester, UNKNOWN: John Wiley \& Sons, Incorporated; 2008. Available from:

http://ebookcentral.proquest.com/lib/griffith/detail.acti on?doclD=351070 
14. Omachonu V, Einspruch N. Innovation in Healthcare Delivery Systems: A Conceptual Framework. Innov J Public Sect Innov J [Internet]. 2010;15(1): Article-2. Available from: http://www.innovation.cc/scholarlystyle/omachonu_healthcare_3innovate2.pdf 15. Damanpour F. Organizational Complexity and Innovation: Developing and Testing Multiple Contingency Models. Manage Sci [Internet]. 1996;42(5):693-716. Available from: http://pubsonline.informs.org/doi/abs/10.1287/mnsc.4 2.5.693

16. Gault F. Defining and measuring innovation in all sectors of the economy. Res Policy. 2018;47(3):617-22. 17. Fleuren M, Wiefferink K, Paulussen T. Determinants of innovation within health care organizations. Literature review and Delphi study. Int J Qual Heal Care. 2004;

18. Greenhalgh T, Robert G, Macfarlane F, Bate P, Kyriakidou O. Diffusion of Innovations in Service Organizations: Systematic Review and Recommendations. Milbank Q [Internet]. Blackwell Publishing, Inc.; 2004;82(4):581-629. Available from: http://dx.doi.org/10.1111/j.0887-378X.2004.00325.x 19. Damanpour F, Aravind D. Managerial Innovation: Conceptions, Processes, and Antecedents. Manag Organ Rev. 2012;8(2):423-54.

20. Chaudoir SR, Dugan AG, Barr CHI. Measuring factors affecting implementation of health innovations: a systematic review of structural, organizational, provider, patient, and innovation level measures. Implement Sci [Internet]. 2013 Nov 15; 8:22. Available from: http://go.galegroup.com.ezp01.library.qut.edu.au/ps/i.d o ?id=GALE\%7CA323032480\&v=2.1\&u=qut\&it=r\&p=HRC A\&asid=b5da59a0ced415b114d65816d989f35f

21. Crossan MM, Apaydin M. A multi-dimensional framework of organizational innovation: A systematic review of the literature. J Manag Stud. 2010;47(6):115491.

22. Salter A, Alexy O. The Nature of Innovation. Oxford Handb Innov Manag. 2013;(February):26-49.

23. Rao J, Weintraub J. What's Your Company's Innovation Quotient. Strategy. 2009;(1):1-9. 24. Rao J, Weintraub J. How Innovative Is Your Company's Culture? MIT Sloan Manag Rev. 2013;54(54315):29-37.

25. Fox A, Gardner G, Osborne S. Theoretical frameworks to support research of health service innovation. Aust Heal Rev [Internet]. 2014;39(1):70-5. Available from: http://eprints.qut.edu.au/77619/ 26. Greenhalgh T, Robert G, Bate P, Macfarlane F, Kriakryidou O. Diffusion of innovations in health service organisations: a systematic literature review [Internet]. Malden, Mass: Blackwell; 2005. Available from: http://griffith.summon.serialssolutions.com/2.0.0/link/0 /eLvHCXMwpV3NT4MwFH_RmRiNB51fbDOp3megtBTO 6uLFm_dmlJIYDRhhxj9_ry0wmB8Xb5RHaftr8j77XgFCeuv Pt3iCSgSnqdKoHcR5yFQcsWVmhD1XqH_n_NeDIGauCn6ucs5dSZY52mxsTge2nR04aONTUVsDXgqEnM hU9LW4dkQbbulo-A6XFavyHOQH9UVii

27. Martins J, Isouard G. An evidence-based framework: Competencies and skills for managers in Australian health services. Asia Pacific J Heal Manag [Internet].
2015;10(2):8. Available from:

https://ezp.lib.unimelb.edu.au/login?url=https://search. ebscohost.com/login.aspx?direct=true $\& \mathrm{db}=$ edsihc $\& A N=$ 445723435883133\&site=eds-

live\&scope=site\%5Cnhttp://search.informit.com.au/doc umentSummary; $\mathrm{dn}=445723435883133$; res=IELAPA

28. Melder A, Killion S. Redesign and innovation in hospitals: foundations to making it happen. 2015. 29. Griffith University. The Griffith Graduate [Internet]. 2016. p. 1-2. Available from: http://policies.griffith.edu.au/pdf/The Griffith Graduate.pdf 30. La Trobe University. Graduate Capabilities [Internet]. 2017 [cited 2017 Jan 12]. Available from:

http://www.latrobe.edu.au/dvca/la-trobeframework/graduate-capabilities 31. University of Western Sydney. Graduate Attributes [Internet]. 2017 [cited 2017 Dec 1]. Available from: https://www.westernsydney.edu.au/learning_futures/h ome/ct/curriculum/graduate_attributes

32. Australian College of Health Services Management. ACHSM Master Health Service Management Competency Framework. 2016.

33. Roth A, Kim H, Care E. New data on the breadth of skills movement: Over 150 countries included [Internet]. 2017 [cited 2017 Nov 20]. Available from:

https://www.brookings.edu/blog/education-plusdevelopment/2017/08/31/new-data-on-the-breadth-ofskills-movement-over-150-countries-included/ 34. Messum D, Wilkes L, Jackson D. Employability Skills: Essential requirements in Health Manager Vacancy Advertisements. Asia Pacific J Heal Manag.

2011;6(2):22-8.

35. Messum DG, Wilkes L, Jackson D, Wilkes L. What Employability Skills are Required of New Health Managers? Asia Pacific J Heal Manag. 2015;28-36. 36. Pellegrino JW, Hilton ML. Education for Life and Work: Developing Transferable Knowledge and Skills in the 21st Century [Internet]. National Academies Press; 2012. Available from:

http://www.nap.edu/catalog/13398

37. Hilton ML. Preparing students for life and work. Issues Sci Technol. 2015; Summer.

38. Harrington $\mathrm{H}$, Voehl F. Innovation Management: A Breakthrough Approach to Organizational Excellence Part 1. Int J Innov Sci [Internet]. 2013;5(4):213-24. Available from: http://multiscience.atypon.com/doi/10.1260/1757-2223.5.4.213 39. Avramenko A. Enhancing students' employability through business simulation. Educ + Train [Internet]. 2012;54(5):355-67. Available from: http://dx.doi.org/10.1108/00400911211244669 